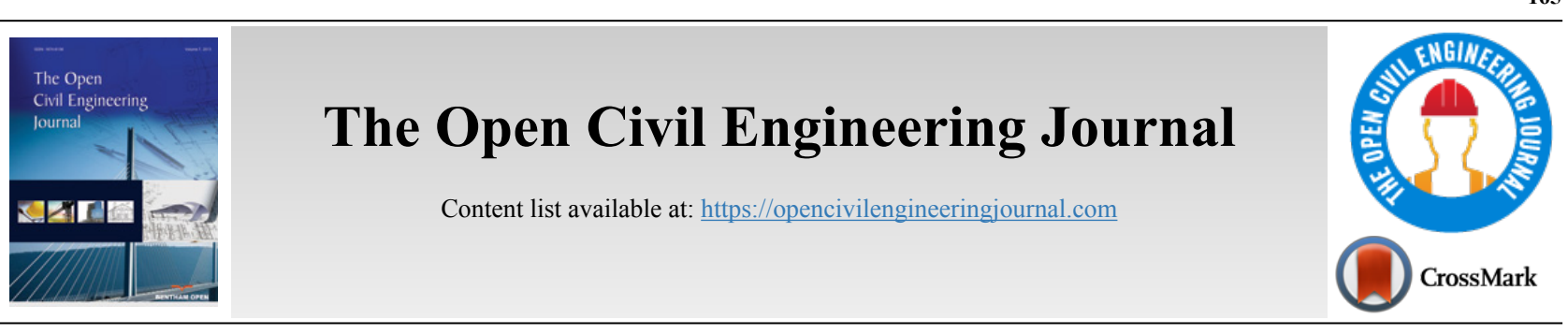

RESEARCH ARTICLE

\title{
Improvement of Flexural and Compressive Strength of Cement Mortar by Graphene Nanoplatelets
}

\author{
Yu Chen ${ }^{1}$, Xingchen $\mathrm{Li}^{1, *}$, Chuangchuang $\mathrm{Li}^{1}$, Nana Zhang ${ }^{1}$, Ronggui Liu ${ }^{1}$ and Chunhua $\mathrm{Lu}^{1}$ \\ ${ }^{1}$ Department of Civil Engineering, Faculty of Civil Engineering and Mechanics, Jiangsu University, Zhenjiang-212013, China
}

\begin{abstract}
:
Background:

In order to provide space for improving the durability of engineering structures by enhancing strength, the addition of nanomaterials has become a research trend in recent years. Graphene and its derivatives have unique properties and have been used in certain fields, which has also stimulated continuous and in-depth research on whether it can improve structural strength.

Objective:

This paper investigates the mechanical properties and mechanism of cement-based materials reinforced by Graphene Nanoplatelets (GNPs).

Methods:

Macroscopically, the flexural strength and compressive strengths of cement mortar were tested. Microscopically, the structure and composition were characterized and analyzed by SEM, EDS, and XRD.

Results:

The results show that the mechanical properties of modified cement mortar are directly related to the GNPs content. When the GNPs content is $0.04 \mathrm{wt} \%$, the flexural and compressive strength can still be increased by $12.8 \%$ and $33.9 \%$ after $28 \mathrm{~d}$. Furthermore, the appropriate content of GNPs dispersed in the cement matrix played a role in promoting cement hydration. The interconnection with hydration products further reduces cracks and pores so that the cement composites form a denser microstructure.

\section{Conclusion:}

The results obtained above would provide references for understanding the reinforcement mechanism of GNPs.
\end{abstract}

Keywords: Graphene nanoplatelets (GNPs), Cement mortar, Flexural strength , Compressive strength , Hydration , Microstructure .

\begin{tabular}{|l|l|l|l|}
\hline Article History & Received: January 11, 2021 & Revised: April 12, 2021 & Accepted: April 25, 2021
\end{tabular}

\section{INTRODUCTION}

At present, cement-based materials are still the most widely used in building and construction fields [1, 2]. However, it has poor durability and high maintenance costs due to high brittleness, easy cracking, low toughness, and low tensile strength $[3-6]$. This limits the application to a certain extent. Therefore, many researchers seek new methods to meet the high-performance requirements of cement-based materials $[7-9]$.

It has been found that nanomaterials can control the gene-

* Address correspondence to this author at Department of Civil Engineering, Faculty of Civil Engineering and Mechanics, Jiangsu University, Zhenjiang212013, China; E-mail: lixingchen_ujs@163.com ration of microcracks at the nanoscale through a series of explorations in recent years, which provides more effective enhancements to the properties of materials $[10,11]$. As a kind of nanomaterial, graphene has been used in cement-based materials due to its excellent chemical, mechanical, electrical, optical, and thermal properties $[12,13]$. All along, the research on Carbon Nanotubes (CNTs) or Graphene Oxide (GO) has been relatively active. However, research on Graphene Nanoplatelets (GNPs), which are also graphene derivatives, are not rich enough $[14,15]$.

GNPs are composed of graphene sheets with a thickness of less than $100 \mathrm{~nm}$ and a diameter of a few microns. GNPs are difficult to disperse in aqueous solutions and other solvents due 
to their small particle size and strong van der Waals force between molecules. So, its dispersion in composite materials is the primary factor $[16,17]$. A related study has found that the combination of surfactant and ultrasonic vibration can achieve stable dispersion of graphene in the matrix without destroying the original structure and excellent performance of graphene [18]. For the modified cement-based materials, related research showed that adding appropriate content of GNPs can improve the mechanical properties of the cement-based materials. Wang et al. [19] found that the GNPs-cement composite exhibited better mechanical properties with the help of surface-modified GNPs. The flexural strength of cement paste increased up to $15 \% \sim 24 \%$ with $0.05 \mathrm{wt} \%$ GNPs (by weight of cement). Meanwhile, the compressive strength of the GNPs-cement composite increased up to $3 \%-8 \%$. Tao et al. [20] also investigated the effect of graphene nanoplatelets (GNPs) on the microstructure and mechanical properties of cement mortar. The results showed that appropriate incorporations of GNPs in cement mortars could densify the microstructure and enhance the mechanical properties. Similar research results can also be seen in other literature [21, 22]. However, some studies have shown that excessive GNPs will have a negative effect. For example, Sun et al. [23] even reported two percolation dosages of GNPs. The large content of GNPs in the cement matrix would lead to a significant drop in mechanical properties, which limits the uses of GNPs-cement composites as structure materials consequentially. In addition, it is also cost-competitive compared with other graphene materials [24]. Thus, the application of GNPs in industrial production and improving the performance of composite materials also have research significance.

Considering the conditions available in this research institute, GNPs dispersion solution were prepared by using Polycarboxylate Superplasticizer (PS) as a surfactant and combining with the dispersion method of ultrasonic vibration. Modified cement mortar specimens with GNPs (dispersion concentrations of $0.00 \%, 0.02 \%, 0.04 \%, 0.06 \%, 0.08 \%$ and $0.10 \%$ by weight) were fabricated successfully. In order to study the mechanical properties, the flexural and compressive strength were first tested. Then the microstructure and composition were characterized by Scanning Electron Microscope (SEM), Energy Spectrometer (EDS), and X-ray Diffractometer (XRD), which were used as mechanism analysis.

\section{MATERIALS AND METHODS}

\subsection{Materials}

The chemical composition and content of Portland cement (P.O 42.5) produced by Jiangsu Beigu Cement Plant are listed in Table 1. The gradation curve of China ISO standard sand (CISS) obtained from Xiamen ISO Standard Sand Co., Ltd. is shown in Fig. (1), meeting the requirements of "Sand for construction" (GB/T 14684-2011). Its distribution curve is completely in Zone II, indicating that its gradation fully meets the use requirements of sand. This not only makes the friction, water retention, and tamping properties of cement mortar mixture better but also makes the shrinkage of the cement mortar smaller. Tap water is used in this study. The physical properties of GNPs purchased from Suzhou Tanfeng Graphene Technology Co., Ltd. are listed in Table 2. The performance parameters of PS dispersing GNPs purchased from Shanghai Chenqi Chemical Technology Co., Ltd. are listed in Table 3.

Table 1. Chemical composition and content of cement.

\begin{tabular}{|c|c|c|}
\hline No. & Chemical Composition & Content (\% by Weight) \\
\hline 1 & $\mathrm{CaO}$ & 65.8 \\
\hline 2 & $\mathrm{SiO}_{2}$ & 21.6 \\
\hline 3 & $\mathrm{Al}_{2} \mathrm{O}_{3}$ & 4.3 \\
\hline 4 & $\mathrm{Fe}_{2} \mathrm{O}_{3}$ & 2.6 \\
\hline 5 & $\mathrm{MgO}$ & 1.2 \\
\hline 6 & $\mathrm{SO}_{3}$ & 1.6 \\
\hline 7 & $\mathrm{~K}_{2} \mathrm{O}$ & 0.7 \\
\hline 8 & $\mathrm{Na}_{2} \mathrm{O}$ & 0.4 \\
\hline 9 & $\mathrm{LOI}$ & 1.8 \\
\hline
\end{tabular}

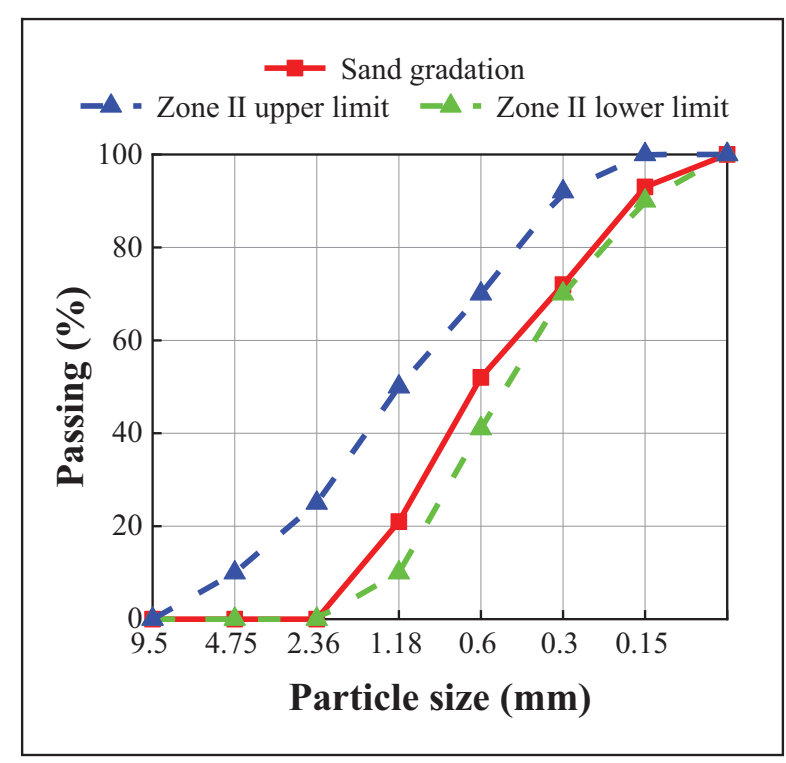

Fig. (1). Grading curve of China ISO standard sand (CISS).

Table 2. Physical properties of GNPs.

\begin{tabular}{|c|c|c|c|c|}
\hline Appearance & $\begin{array}{c}\text { Sheets Diameter } \\
(\boldsymbol{\mu m})\end{array}$ & Thickness $(\mathbf{n m})$ & $\begin{array}{c}\text { Surface Area } \\
\left(\mathbf{m}^{2} / \mathbf{g}\right)\end{array}$ & $\mathbf{P H}$ \\
\hline Black powder & $10.0 \sim 50.0$ & $3.4 \sim 8.0$ & 191.8 & 7.0 \\
\hline
\end{tabular}

Table 3. Performance parameters of PS.

\begin{tabular}{|c|c|c|c|c|}
\hline Appearance & $\mathbf{P H}$ & $\begin{array}{c}\text { Moisture } \\
\text { Content } \\
\mathbf{( \% )}\end{array}$ & $\begin{array}{c}\text { Cement } \\
\text { Paste } \\
\text { Fluidity } \\
\mathbf{( m m )}\end{array}$ & $\begin{array}{c}\text { Mortar Water } \\
\text { Reduction Rate } \\
\mathbf{( \% )}\end{array}$ \\
\hline Off-white powder & 7.1 & 1.8 & 280.0 & 16.0 \\
\hline
\end{tabular}

\subsection{Mix Design}

6 levels of mix ratios are listed in Table 4 referring to the "Method of testing cements-Determination of strength (ISO)" (GB/T 17671-1999). The water-cement ratio was fixed at 
Table 4. Mix design of GNPs modified cement mortar.

\begin{tabular}{|c|c|c|c|c|c|c|}
\hline Specimens & W/C & Cement (g) & Sand (g) & Water (g) & GNPs (g) & PS (g) \\
\hline M1 (0.00wt\% GNPs) & 0.425 & 450 & 1350 & 191.25 & 0.00 & 0.9 \\
\hline M2 (0.02wt\% GNPs) & 0.425 & 450 & 1350 & 191.25 & 0.09 & 0.9 \\
\hline M3 (0.04wt\% GNPs) & 0.425 & 450 & 1350 & 191.25 & 0.18 & 0.9 \\
\hline M4 (0.06wt\% GNPs) & 0.425 & 450 & 1350 & 191.25 & 0.27 & 0.9 \\
\hline M5 (0.08wt\% GNPs) & 0.425 & 450 & 1350 & 191.25 & 0.36 & 0.9 \\
\hline M6 (0.10wt\% GNPs) & 0.425 & 450 & 1350 & 191.25 & 0.45 & 0.9 \\
\hline
\end{tabular}

0.425 . The contents of GNPs were $0.00 \%, 0.02 \%, 0.04 \%$, $0.06 \%, 0.08 \%$ and $0.10 \%$ of the mass of the cement, respectively. The content of PS was $0.20 \%$ of the mass of the cement, referring to the recommended content of its material production plant. The water consumption of it containing working conditions is reduced by $15 \%$ because PS plays the role of water reducing agent. GNPs were added into cement instead of water in the same way as an aqueous solution.

\subsection{Preparation of GNPs Suspension}

The van der Waals force of GNPs will make it agglomerate in an aqueous solution. Therefore, it is necessary to effectively disperse it to obtain a uniform dispersion solution. Fig. (2) shows the entire preparation process of GNPs suspension. PS was first mixed with one-third of the total water. PS solution was obtained by hand stirring for $1 \mathrm{~min}$ and ultrasonic vibration for approximately $5 \mathrm{~min}$. Then the weighted GNPs were added to obtain uniform suspension by hand stirring for 1 $\mathrm{min}$ and ultrasonic vibration for approximately $30 \mathrm{~min}$.

\subsection{Fabrication and Curing of Specimens}

After stirring for $3 \mathrm{~min}$, the cement mortar was cast into the mold with a size of $40 \mathrm{~mm} \times 40 \mathrm{~mm} \times 160 \mathrm{~mm}$ and shook on a shaker for $2 \mathrm{~min}$ (60 times/min). Specimens were demoulded after $24 \mathrm{~h}$ and immediately placed in a standard curing box (the temperature is $20 \pm 2{ }^{\circ} \mathrm{C}$, the relative humidity is above $90 \%$ ) for $7 \mathrm{~d}, 14 \mathrm{~d}$, and $28 \mathrm{~d}$.

\subsection{Test Methods}

The mechanical properties of cement mortar were tested by a DY-208JX full-automatic pressure testing machine according to the "Method of testing cements-Determination of strength (ISO)" (GB/T 17671-1999). The morphological characteristics of cement mortar were studied by an S-3400N SEM (Hitachi from Japan). The samples for SEM were taken from the middle of the section of the mortar specimen, which had been subjected to the flexural and compressive tests. The cement mortar hydration product composition was studied by a D8 ADVANCE XRD (BRUKER from Germany). The specimens for XRD was crushed into powders and passed through a sieve of $80 \mu \mathrm{m}$. Then a certain amount of powder was taken for XRD testing. The scanning angle $(2 \theta)$ ranged from $5^{\circ}$ to $90^{\circ}$ and the scanning step size was $0.02^{\circ}$ at a rate of $0.5 \mathrm{~s}$ per step.

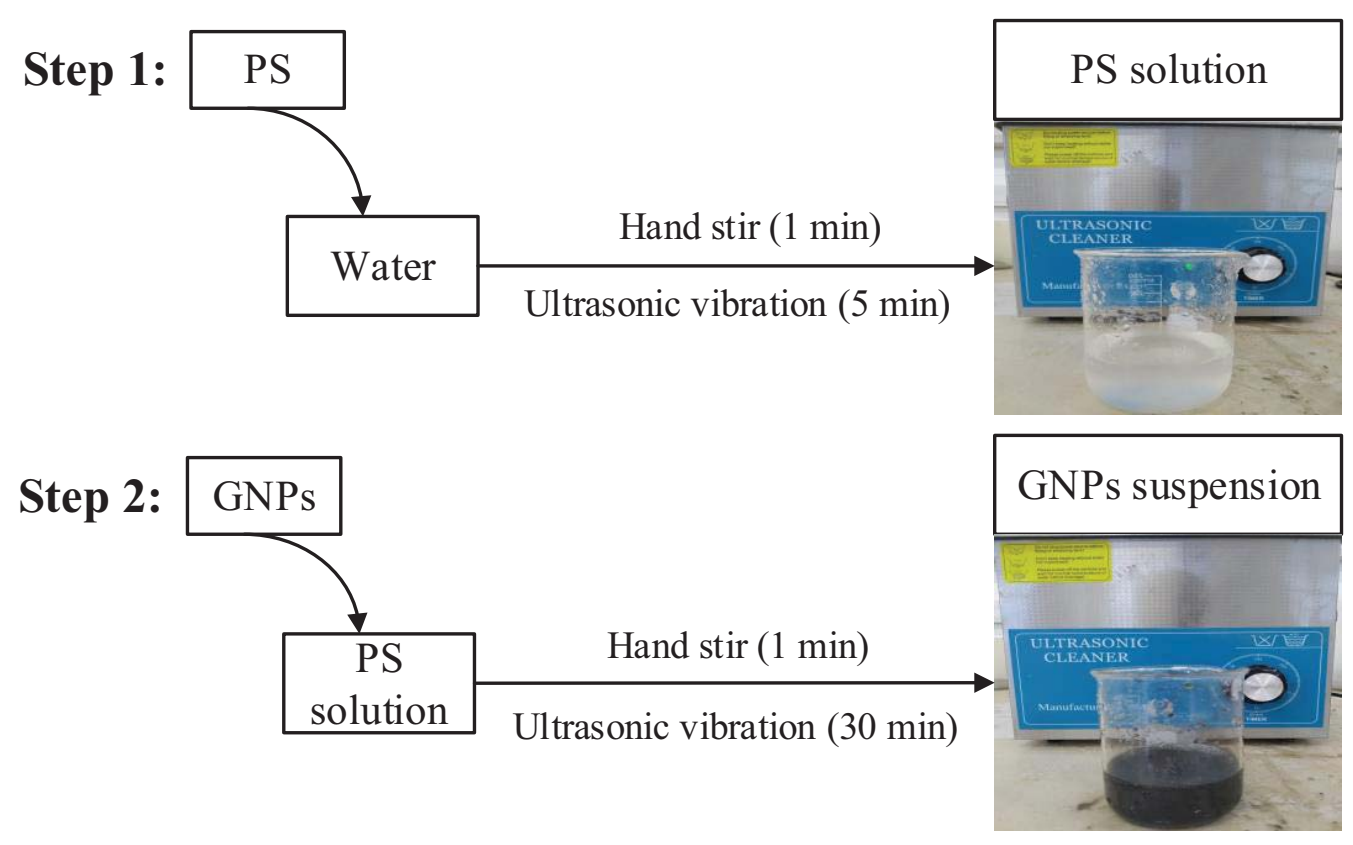

Fig. (2). Preparation process of GNPs suspension. (The ultrasonic frequency is $40 \mathrm{kHz}$. The ultrasonic power is $120 \mathrm{~W}$.) 


\section{RESULTS AND DISCUSSION}

\subsection{Mechanical Properties}

Figs. (3 and 4) showed that the flexural and compressive strength of cement mortar with different contents of GNPs dispersed after $7 \mathrm{~d}, 14 \mathrm{~d}$, and $28 \mathrm{~d}$. Standard deviations of strength in all specimens are small, implying a uniform dispersion of GNPs in cement mortar as well as stable and reliable results.

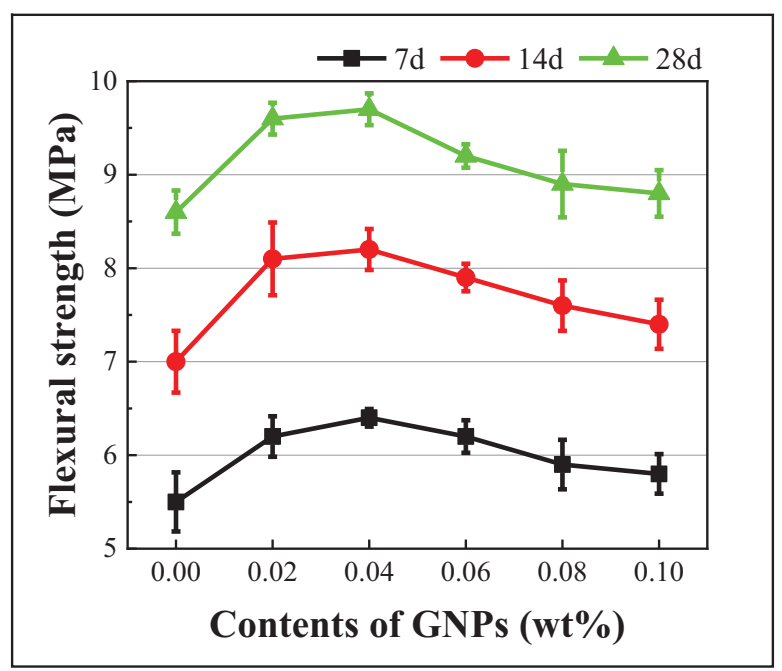

Fig. (3). Flexural strength of GNPs modified cement mortar.

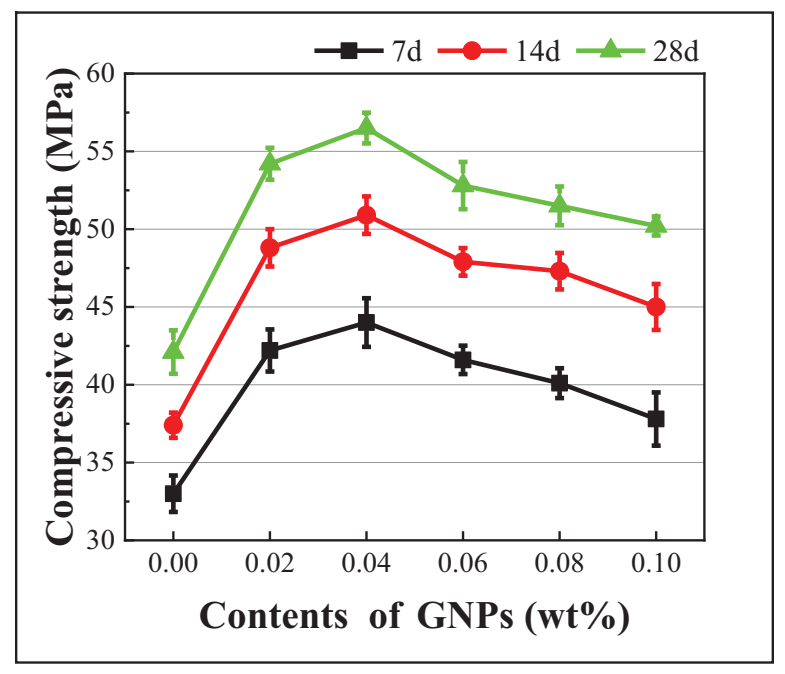

Fig. (4). Compressive strength of GNPs modified cement mortar.

It can be seen that the flexural and compressive strengths of GNPs modified cement mortar increase with curing time prolongs when the water-cement ratio is constant. This is due to the continuous hydration of cement. The most important point is that the flexural and compressive strengths of cement mortar are also improved with the addition of GNPs, which can be attributed to the "filler effect" for accelerating the hydration reactions of the cementitious materials [25]. When the content of GNPs is in the range of $0 \sim 0.04 \mathrm{wt} \%$, the strength increases.
When the content of GNPs is in the range of $0.04 \sim 0.10 \mathrm{wt} \%$, the strength shows a downward trend. This trend has also been reported in other similar studies $[20,26]$. The flexural and compressive strengths of M3 $(0.04 \mathrm{wt} \%$ GNPs $)$ have the maximum value on the basis of this experiment. The flexural strength reaches 6.4 MPa, 8.2 $\mathrm{MPa}$, and 9.7 $\mathrm{MPa}$ after $7 \mathrm{~d}, 14$ $\mathrm{d}$, and $28 \mathrm{~d}$. The compressive strength reaches $44.0 \mathrm{MPa}, 50.9$ $\mathrm{Mpa}$, and 56.5 $\mathrm{MPa}$, respectively. Compared with ordinary cement mortar M1 $(0.00 \mathrm{wt} \%$ GNPs $)$, the flexural strength increases by $16.4 \%, 17.1 \%$, and $12.8 \%$, while the compressive strength increases by $33.3 \%, 36.1 \%$, and $33.9 \%$, respectively. This reveals that the appropriate content of GNPs has a great influence on the strength of cement mortar. When GNPs exceed a certain content, their strength decreases. The reason for the preliminary analysis may be that the content of GNPs affects its dispersion effect on the cement matrix. Low or appropriate content of GNPs should be well dispersed after ultrasonic vibration, which is easy to combine with the cement matrix. Agglomeration will occur if it is excessive, resulting in poor dispersion and no effect of continued enhancement.

Furthermore, the above results are compared with other documents shown in Table 5. In terms of the strength increase rate after $28 \mathrm{~d}$, the GNPs in the current study have the potential to improve the mechanical properties, especially the compressive strength can be increased by $33.9 \%$. The reason may be due to the physical properties of GNPs, such as shape and morphology [27]. Reference [28] also has proven that the inconsistent regularity of compressive strength and flexural strength of reinforced concrete is enhanced by nano-silica and other nanomaterials.

Table 5. Comparison of existing strength values with current study.

\begin{tabular}{|c|c|c|c|c|c|}
\hline Matrix & W/C & $\begin{array}{c}\text { GNPs } \\
\text { Contents } \\
\text { (wt\%) }\end{array}$ & \multicolumn{2}{|c|}{$\begin{array}{c}\text { Increase Rate after 28 d } \\
\text { (\%) }\end{array}$} & \multirow{2}{*}{ Reference } \\
\cline { 4 - 5 } & & $\begin{array}{c}\text { Flexural } \\
\text { Strength }\end{array}$ & $\begin{array}{c}\text { Compressive } \\
\text { Strength }\end{array}$ & \\
\hline Mortar & 0.425 & 0.04 & 12.8 & 33.9 & $\begin{array}{c}\text { Current } \\
\text { Study }\end{array}$ \\
\hline Mortar & 0.367 & 0.05 & 15.6 & 8.3 & {$[20]$} \\
\hline Paste & 0.300 & 0.06 & 27.8 & 11.0 & {$[29]$} \\
\hline
\end{tabular}

\subsection{SEM Characterization and EDS Analysis}

In order to obtain a deeper insight into the influence mechanism of the above GNPs on the flexural and compressive strength of cement mortar, the microstructure of three key specimens (M1, M3, and M6) was characterized by SEM at a high magnification of 5.00k. EDS analysis was performed on area 1, 2 and 3 in the SEM image to confirm the presence of GNPs in the cement matrix and its effect on the hydration products. The area 1, 2, and 3 in the SEM image are controlled to be equal during analysis. The results are shown in Fig. (5). Due to mechanical pressure and other reasons in the specimen preparation process, there is a gap in the micro-morphology of the ordinary cement matrix (M1). The fibrous C-S-H crystals and the prism ettringite (AFt) produced by cement hydration are disorderly arranged. This is macroscopically obvious holes and cracks, which will make the overall structure uneven and have a great negative impact on performance. On the contrary, 
the addition of GNPs made the cement hydration products more abundant. It overlapped with products (C-S-H and AFt) to form a layered structure, which was denser without obvious pores and was stacked in an orderly manner. This means that GNPs may play a role in adjusting the shape of hydrated products and filling the gaps and pores of the cement matrix. This is beneficial to delay the extension of microcracks, thereby improving the mechanical properties of cement mortar. When the content of GNPs rises to $0.10 \mathrm{wt} \%$, sheet-like aggregates could be observed. It is speculated that this phenomenon is caused by the aggregation of GNPs. GNPs might pile up into a block and might not be combined with the surrounding cement matrix when its content is too high. Therefore, it will reduce the density of the structure and cause the mechanical properties of the cement mortar to decrease. It can be judged from Fig. (5) that the hydration products of cement-based materials are mainly composed of $\mathrm{Ca}, \mathrm{Si}, \mathrm{O}, \mathrm{C}$, $\mathrm{Al}, \mathrm{S}, \mathrm{Na}$, and $\mathrm{Fe}$. The content of $\mathrm{Ca}, \mathrm{Si}$, and $\mathrm{O}$ element are relatively high in area 1 , indicating that the area selected contains hydration products (AFt, C-S-H crystals). Both grow alternately, which is consistent with the SEM image. Besides, the content of $\mathrm{Ca}$ and $\mathrm{C}$ elements in area 2 increases. It not only demonstrates that the dispersion method of ultrasonic vibration could disperse GNPs into cement-based materials but also indicates that the lamella structure observed is indeed formed by the addition of $0.04 \mathrm{wt} \%$ GNPs. Due to nano-size of GNPs, it plays a significant role in the pore filling process, reducing the porosity of cement-based materials and improving the microstructure. Further, it can be seen that the content of the $\mathrm{Ca}$ element continues to increase in area 3 while the content of the $\mathrm{Si}$ and $\mathrm{O}$ element decreases. This might imply that the high content of GNPs is aggregated in the selected area. It has a certain influence on the growth form and quantity distribution of hydration products, reducing the performance improvement effect and matching the actual situation. Based on the above analysis, this further confirms the judgment in Section 3.1 that the proper content of GNPs can successfully limit the propagation of cracks using its own structure. It is conducive to the improvement of the strength of cement-based materials.
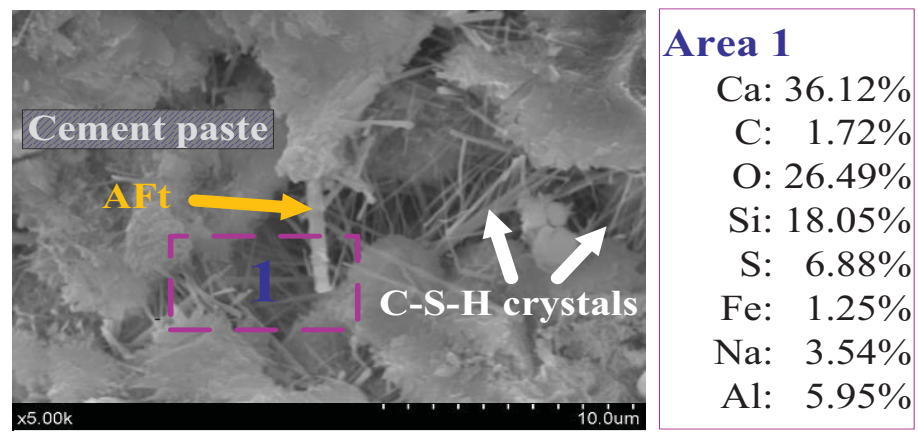

M1 (0.00wt\% GNPs)

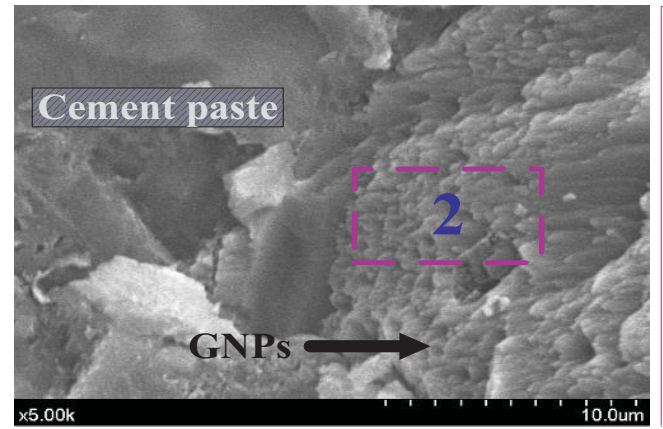

\section{Area 2}

Ca: $41.73 \%$

C: $7.15 \%$

O: $24.49 \%$

Si: $10.43 \%$

S: $8.70 \%$

Fe: $1.75 \%$

Na: $2.60 \%$

Al: $3.14 \%$

M3 (0.04wt\% GNPs)

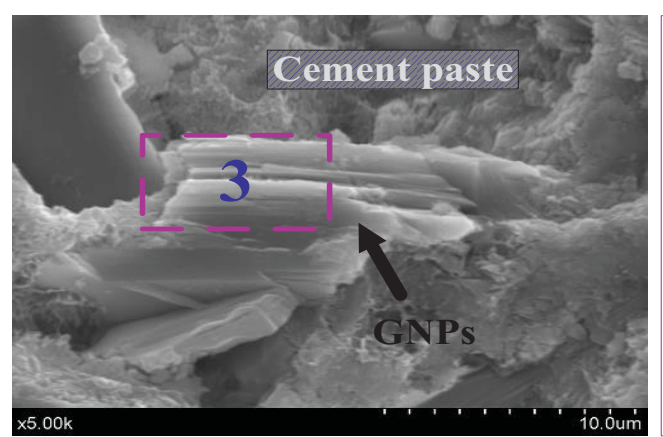

Area 3

Ca: $56.05 \%$

C: $8.65 \%$

O: $9.92 \%$

Si: $10.99 \%$

S: $8.01 \%$

Fe: $1.20 \%$

Na: $1.87 \%$

Al: $3.33 \%$

M6 (0.10wt\% GNPs)

Fig. (5). SEM images and EDX spectrum analysis of M1, M3, and M6 after $28 \mathrm{~d}$ curing. 


\subsection{XRD Analysis}

In order to further analyze the impact of GNPs on cement hydration products, XRD tests were also performed on specimens (M1, M3, and M6) after $28 \mathrm{~d}$. The results are shown in Fig. (6). It can be seen that the main crystal products of cement hydration include calcium hydroxide $(\mathrm{CH})$, hydrated calcium silicate $(\mathrm{C}-\mathrm{S}-\mathrm{H})$, ettringite $(\mathrm{AFt})$, and calcium sulfoaluminate hydrates (AFm). $\mathrm{CH}$ and $\mathrm{C}-\mathrm{S}-\mathrm{H}$ represent the continuous hydration of cement and the regulation mechanism of hydration. By comparison, it is found that the trend of the diffraction peak curves of M3 and M6 is similar to that of M1. The positions of the diffraction peaks of the main crystal products are the same, but the intensity is slightly different. It is found that no new crystal diffraction peak appeared. Due to the addition of GNPs in M3 and M6, the diffraction intensity of $\mathrm{CH}$ at the diffraction peaks represented by $20^{\circ}, 36^{\circ}$, and $60^{\circ}$ significantly decreased. Perhaps this manifests that GNPs can promote the hydration reaction of cement. It has no effect on the type of hydration crystal formation and only has a certain inhibitory effect on the formation of hydration products. However, the diffraction peak intensity of products $\mathrm{CH}, \mathrm{C}-\mathrm{S}-\mathrm{H}$, and AFt will be slightly improved compared to M3 and M6. This signifies that the crystallinity of $\mathrm{CH}, \mathrm{C}-\mathrm{S}-\mathrm{H}$, and AFt is high. It is speculated the reason is that excess GNPs cannot be dispersed more effectively, affecting their binding ability with hydration products. It also indirectly causes cracks in the cement matrix and reduces the macro-mechanical effect. Therefore, the above analysis further explains why GNPs can play a role in strengthening and toughening cement mortar.

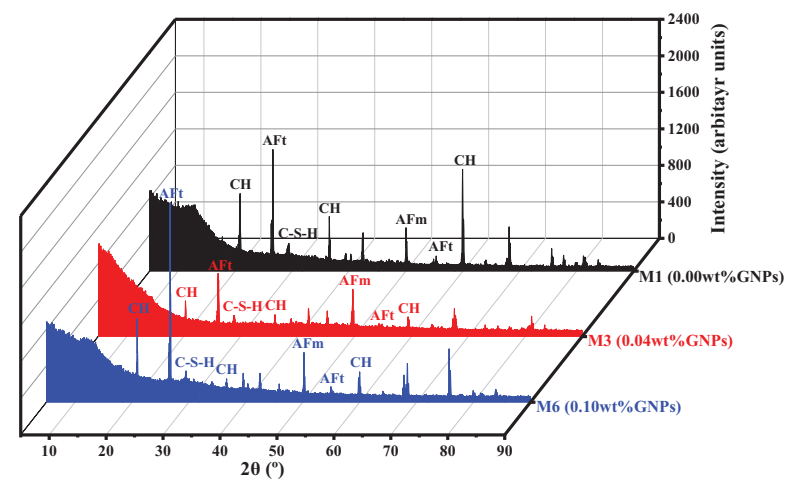

Fig. (6). XRD spectrums of M1, M3, and M6 after 28d curing.

\section{CONCLUSION}

This paper explores the effect of GNPs on the flexural and compressive properties of cement mortar. The conclusions are summarized as follows:

[1] Adding appropriate content of GNPs could improve the mechanical properties of cement mortar. Based on the background, conditions, and methods of the current study, $0.04 \mathrm{wt} \%$ GNPs achieves the best performance that the flexural and compressive strength of reinforced cement mortar increased by $12.8 \%$ and $33.9 \%$ after $28 \mathrm{~d}$, respectively.

[2] The appropriate content of GNPs could improve the microstructure of cement mortar. $0.04 \mathrm{wt} \%$ GNPs can be effectively dispersed into the cement matrix and fill the internal cracks and pores, which is beneficial to improve the density of the overall structure.

[3] The appropriate content of GNPs could promote cement hydration. After $0.04 \mathrm{wt} \%$ GNPs participated in the hydration reaction, it generated new hydration products and also effectively inhibited the formation of $\mathrm{CH}$ crystals in the hydration products.

The results obtained in this investigation suggest that GNPs have the potential for use as nano-reinforcement in cement composites materials. However, it needs further study as to what content is added to other types of cement-based composites and how it affects the strength. In addition, it is necessary to apply this nano-scale crack "repair" technology to the maintenance and reinforcement of future engineering structures.

\section{CONSENT FOR PUBLICATION}

Not applicable.

\section{AVAILABILITY OF DATA AND MATERIALS}

The authors confirm that the data supporting the findings of this study are available within the article.

\section{FUNDING}

This work was supported by the National Natural Science Foundation of China (grant numbers 51778272 and 51878319).

\section{CONFLICT OF INTEREST}

The authors declare no conflicts of interest, financial or otherwise.

\section{ACKNOWLEDGEMENTS}

The authors are grateful to the Jiangsu University for providing the laboratory where this research was performed. The work was not conducted without guidelines and consideration.

\section{REFERENCES}

[1] S.H. Lv, Y.M. Ma, C.C. Qiu, T.S. Sun, J.J. Liu, and Q.F. Zhou, "Effect of graphene oxide nanosheets of microstructure and mechanical properties of cement composites", Constr. Build. Mater., vol. 49, pp. 121-127, 2013.

[http://dx.doi.org/10.1016/j.conbuildmat.2013.08.022]

[2] B.M. Wang, and B. Pang, "Mechanical property and toughening mechanism of water reducing agents modified graphene nanoplatelets reinforced cement composites", Constr. Build. Mater., vol. 226, pp. 699-711, 2019.

[http://dx.doi.org/10.1016/j.conbuildmat.2019.07.229]

[3] J. Tashan, and R. Al-Mahaidi, "Detection of cracks in concrete strengthened with CFRP systems using infra-red thermography", Compos., Part B Eng., vol. 64, pp. 116-125, 2014 [http://dx.doi.org/10.1016/j.compositesb.2014.04.011]

[4] R.V. Sagar, B.K.R. Prasad, and S.S. Kumar, "An experimental study on cracking evolution in concrete and cement mortar by the b-value analysis of acoustic emission technique", Cement Concr. Res., vol. 42, no. 8, pp. 1094-1104, 2012.

[http://dx.doi.org/10.1016/j.cemconres.2012.05.003]

[5] C. Fu, C. Xie, J. Liu, X. Wei, and D. Wu, "A comparative study on the effects of three nano-materials on the properties of cement-based composites", Materials (Basel), vol. 13, no. 4, pp. 857-871, 2020. [http://dx.doi.org/10.3390/ma13040857] [PMID: 32070022] 
[6] W.J. Long, J.J. Wei, F. Xing, and K.H. Khayat, "Enhanced dynamic mechanical properties of cement paste modified with graphene oxide nanosheets and its reinforcing mechanism", Cement Concr. Compos., vol. 93, pp. 127-139, 2018.

[http://dx.doi.org/10.1016/j.cemconcomp.2018.07.001]

[7] J.T. Liu, J.L. Fu, T.Y. Ni, and Y. Yang, "Fracture toughness improvement of multi-wall carbon nanotubes/graphene sheets reinforced cement paste", Constr. Build. Mater., vol. 200, pp. 530-538, 2019.

[http://dx.doi.org/10.1016/j.conbuildmat.2018.12.141]

[8] Y.D. Xu, J.Q. Zeng, W. Chen, R.Y. Jin, B. Li, and Z.H. Pan, "A holistic review of cement composites reinforced with graphene oxide", Constr. Build. Mater., vol. 171, pp. 291-302, 2019.

[http://dx.doi.org/10.1016/j.conbuildmat.2018.03.147]

[9] A. Nieto, A. Bisht, D. Lahiri, C. Zhang, and A. Agarwal, "Graphene reinforced metal and ceramic matrix composites: A review", Int. Mater. Rev., vol. 62, no. 5, pp. 241-302, 2016.

[http://dx.doi.org/10.1080/09506608.2016.1219481]

[10] E. Shamsaei, F.B.D. Souza, X.P. Yao, E. Benhelal, A. Akbari, and W.H. Duan, "Graphene-based nanosheets for stronger and more durable concrete: A review", Constr. Build. Mater., vol. 183, pp. 642-660, 2018.

[http://dx.doi.org/10.1016/j.conbuildmat.2018.06.201]

[11] G. Yıldırım, M.H. Sarwary, A. Al-Dahawi, O. Öztürk, Ö. Anıl, and M. Sahmaran, "Piezoresistive behavior of CF-and CNT-based reinforced concrete beams subjected to static flexural loading: Shear failure investigation", Constr. Build. Mater., vol. 168, pp. 266-279, 2018. [http://dx.doi.org/10.1016/j.conbuildmat.2018.02.124]

[12] K.S. Novoselov, A.K. Geim, S.V. Morozov, D. Jiang, Y. Zhang, S.V. Dubonos, I.V. Grigorieva, and A.A. Firsov, "Electric field effect in atomically thin carbon films", Science, vol. 306, no. 5696, pp. 666-669, 2004.

[http://dx.doi.org/10.1126/science.1102896] [PMID: 15499015]

[13] W. Ren, and H.M. Cheng, "The global growth of graphene", Nat. Nanotechnol., vol. 9, no. 10, pp. 726-730, 2014.

[http://dx.doi.org/10.1038/nnano.2014.229] [PMID: 25286256]

[14] M. Del Carmen Camacho, O. Galao, F.J. Baeza, E. Zornoza, and P. Garcés, "Mechanical properties and durability of CNT cement composites", Materials (Basel), vol. 7, no. 3, pp. 1640-1651, 2014. [http://dx.doi.org/10.3390/ma7031640] [PMID: 28788536]

[15] D. Kang, K.S. Seo, H.Y. Lee, and W. Chung, "Experimental study on mechanical strength of GO-cement composites", Constr. Build. Mater., vol. 131, pp. 303-308, 2017.

[http://dx.doi.org/10.1016/j.conbuildmat.2016.11.083]

[16] S. Ghazizadeh, P. Duffour, N.T. Skipper, M. Billing, and Y. Bai, "An investigation into the colloidal stability of graphene oxide nano-layers in alite paste", Cement Concr. Res., vol. 99, pp. 116-128, 2017. [http://dx.doi.org/10.1016/j.cemconres.2017.05.011]

[17] N.W. Pu, C.A. Wang, Y.M. Liu, Y. Sung, D.S. Wang, and M.D. Ger, "Dispersion of graphene in aqueous solutions with different types of surfactants and the production of graphene films by spray or drop coating", J. of the Taiwan Inst. of Chem. Engs., vol. 43, no. 1, pp. 140-146, 2012. [http://dx.doi.org/10.1016/j.jtice.2011.06.012]

[18] H.J. Du, and S.D. Pang, "Dispersion and stability of graphene nanoplatelet in water and its influence on cement composites", Constr. Build. Mater., vol. 167, pp. 403-413, 2018.

[http://dx.doi.org/10.1016/j.conbuildmat.2018.02.046]

[19] B. Wang, R. Jiang, and Z. Wu, "Investigation of the mechanical properties and microstructure of graphene nanoplatelet-cement composite", Nanomaterials (Basel), vol. 6, no. 11, pp. 200-214, 2016. [http://dx.doi.org/10.3390/nano6110200] [PMID: 28335328]

[20] J. Tao, X.H. Wang, Z.D. Wang, and Q. Zeng, "Graphene nanoplatelets as an effective additive to tune the microstructures and piezoresistive properties of cement-based composites", Constr. Build. Mater., vol. 209, pp. 665-678, 2019.

[http://dx.doi.org/10.1016/j.conbuildmat.2019.03.173]

[21] S. Huang, "Multifunctional graphite nanoplatelets (GNP) reinforced cementitious composites", M.S. thesis, National University of Singapore, Singapore, 2012.

[22] Q. Liu, Q.F. Xu, Q. Yu, R.D. Gao, and T. Tong, "Experimental investigation on mechanical and piezoresistive properties of cementitious materials containing graphene and graphene oxide nanoplatelets", Constr. Build. Mater., vol. 127, pp. 565-576, 2016. [http://dx.doi.org/10.1016/j.conbuildmat.2016.10.024]

[23] S.W. Sun, B.G. Han, S. Jiang, X. Yu, Y.L. Wang, H.Y. Li, and J.P. $\mathrm{Ou}$, "Nano graphite platelets-enabled piezoresistive cementitious composites for structural health monitoring", Constr. Build. Mater., vol. 136, pp. 314-328, 2017.

[http://dx.doi.org/10.1016/j.conbuildmat.2017.01.006]

[24] K.U.R. Sardar, I. Zainah, A.M. Shazim, H.A. Toasin, F. Arbab, M. Kashif, and M.A. Syed, "Influence of graphene nanosheets on rheology, microstructure, strength development and self-sensing properties of cement based composites", Sustainability, vol. 10, no. 3, pp. 822-842, 2018.

[http://dx.doi.org/10.3390/su10030822]

[25] B.G. Han, S.W. Sun, S.Q. Ding, L.Q. Zhang, X. Yu, and J.P. Ou, "Review of nanocarbon-engineered multifunctional cementitious composites", Compos., Part A Appl. Sci. Manuf., vol. 70, pp. 69-81, 2015 .

[http://dx.doi.org/10.1016/j.compositesa.2014.12.002]

[26] H. Liu, M.Q. Sun, J. Li, Y.J. Wang, and X.Y. Zhang, "Piezoresistive effects of cement-based composites containing graphene nanoplatelets", J. of Func. Mate., vol. 46, no. 16, pp. 16064-16068, 2015.

[27] L.W. Li, Q.F. Zheng, S.F. Dong, X.Y. Wang, and B.G. Han, The reinforcing effects and mechanisms of multi-layer graphenes on mechanical properties of reactive powder concrete, vol. 251. Construction and Building Materials, 2020.

[28] G. Long, Y. Shi, K. Ma, and Y. Xie, "Reactive powder concrete reinforced by nanoparticles", Adv. Cement Res., vol. 28, no. 2, pp. 99-109, 2016.

[http://dx.doi.org/10.1680/jadcr.15.00058]

[29] B.M. Wang, and S. Deng, Effect and mechanism of graphene nanoplatelets on hydration reaction, mechanical properties and microstructure of cement composites., vol. 228. Construction and Building Materials, 2019.

\section{(C)2021 Chen. et al.}

This is an open access article distributed under the terms of the Creative Commons Attribution 4.0 International Public License (CC-BY 4.0), a copy of which is available at: https://creativecommons.org/licenses/by/4.0/legalcode. This license permits unrestricted use, distribution, and reproduction in any medium, provided the original author and source are credited. 